\title{
Medications Adherence and Associated Factors among Patients with Type 2 Diabetes Mellitus in the Gaza Strip, Palestine
}

\author{
Aymen Elsous ${ }^{1,2}$, Mahmoud Radwan ${ }^{1,3 *}$, Hasnaa Al-Sharif ${ }^{4}$ and Ayman Abu Mustafa \\ ${ }^{1}$ Department of Health Management and Economics, School of Public Health, Tehran University of Medical Sciences - \\ International campus, Tehran, Iran, ${ }^{2}$ Quality Improvement and Infection Control Office, Shifa Medical Complex, Gaza Strip, \\ Palestine, ${ }^{3}$ Directorate General of International Cooperation, Ministry of Health, Gaza Strip, Palestine, ${ }^{4}$ Director of Chronic \\ Diseases Department, Al Rimal Martyrs Health Center, Ministry of Health, Gaza Strip, Palestine, ${ }^{5}$ Department of Research, \\ Directorate General of Human Resources Development, Ministry of Health, Gaza Strip, Palestine
}

OPEN ACCESS

Edited by: Adeel Safdar,

Humber College, Canada

Reviewed by:

Rosana De Morais Borges Marques, Universidade Federal de Goiás, Brazil Tahir Mehmood Khan, Monash University Malaysia, Malaysia Brian Godman, Karolinska Institutet, Sweden

${ }^{*}$ Correspondence: Mahmoud Radwan mradwan78@hotmail.com

Specialty section: This article was submitted to Diabetes, a section of the journal Frontiers in Endocrinology

Received: 09 April 2017 Accepted: 01 May 2017 Published: 09 June 2017

Citation:

Elsous A, Radwan M, Al-Sharif H and Abu Mustafa A (2017) Medications Adherence and Associated Factors among Patients with Type 2 Diabetes Mellitus in the Gaza Strip, Palestine.

Front. Endocrinol. 8:100. doi: 10.3389/fendo.2017.00100
Aim: The aim of this study was to evaluate the adherence to anti-diabetic medications among patients with type 2 diabetes mellitus (DM) seeking medical care in the Gaza Strip, Palestine.

Methods: A cross-sectional study was conducted among 369 primary care patients with type 2 DM from October to December 2016. Adherence to medications was measured using the Morisky Medication Adherence Scale (MMAS-4). Socio-demographic and clinical variables, provider-patient relationship, health literacy, and health belief were examined for each patient. Univariate, binary logistic regression and multiple linear regression were applied to determine the independent factors influencing adherence to anti-diabetic medications using SPSS version 22.

Results: Of all the respondents, 214 (58\%), 146 (39.5\%), and nine (2.5\%) had high (MMAS score $=0$ ), medium (MMAS score $=1+2$ ), and low (MMAS score $\geq 3$ ) adherence to anti-diabetic medications, respectively. Factors that were independently associated with adherence to anti-diabetic medications were as follows: female gender [odds ratio (OR): 1.657, 95\% confidence interval (Cl): 1.065-2.578] and perception of disease's severity (OR: $1.510,95 \% \mathrm{Cl}: 0.410-5.560)$. Elderly $(t=1.345)$ and longer duration of DM $(t=0.899)$ were also predictors of adherence but showed no statistical significance $(p>0.05)$.

Conclusion: The level of complete adherence to anti-diabetic medications was suboptimal. New strategies that aim to improve patients' adherence to their therapies are necessary taking into consideration the influencing factors and the importance of having diabetes educators in the primary care centers.

Keywords: medication adherence, diabetes mellitus, factors, Palestine, cross-sectional

\section{INTRODUCTION}

Diabetes mellitus (DM) is a serious and a rapidly growing public health problem that affects millions of people. It usually co-exists with other medical conditions, and its prevalence is increasing year by year reaching epidemic proportions. Currently, 387 million people have DM (1) and are expected to 
reach 483 million and 592 million by the year 2030 (2) and 2035 (1), respectively, in which type $2 \mathrm{DM}$ is accounting $90 \%$ of cases (3). DM is responsible for more than $77 \%$ of morbidities and $88 \%$ of deaths in developing countries $(1,4)$.

It is noteworthy mentioning that 15 years later the Arab world in North Africa, the Middle East including Gulf area, is going to have a tremendous increase in the percentage of people having DM compared to other parts of the world (5). According to the International Diabetes Federation, the prevalence of DM in the Middle East and North African region will be the highest compared to other parts of the world (6).

In Palestine, few studies were conducted and the prevalence of DM was higher in urban areas compared to rural areas (7-9). Abu-Rmeileh and colleagues (10) estimated the prevalence of DM in Palestine at 20.8 and $23.4 \%$ in 2020 and 2030, respectively. Reports of the Ministry of Health $(\mathrm{MoH})$ revealed that 27,601 have DM in the Gaza Strip with an incidence rate of 15.4/1,000 (11) and is steadily increasing because Gazian people are in a prolonged state of stress from political uncertainty and frequent violation. DM is known to be the disease of elderly; however, it is now more prevalent among younger age below 55 years old. Patients with DM are in an unhealthy class due to lack of knowledge about the disease and prevention of complications. Moreover, the increasing rate of obesity is the major risk factor for DM (12). Complications from DM, including diabetic foot, were previously studied in Gaza and showed to be significantly associated with a low educational level, low income, and primary care physicians' attitudes $(13,14)$. DM represents $11.2 \%$ of all deaths (11), and half of physicians and nurses do not adhere to Palestinian diabetes guideline because of lack of interest (15) making real challenges to the health care services and proper diabetes management. Diabetic neuropathy is one of the major complications that presents in $12 \%$ of type $2 \mathrm{DM}$ patients and is the leading cause of extremity amputations (11).

Achieving glycemic control and preventing early complications are the ultimate targets of diabetes management which depends on patient's adherence to regimens (16). Adherence to prescribed medications is one of the key dimensions of health care quality, which is defined as the proportion of prescribed doses of medication actually taken by a patient over a specified period of time (17). Adherence to or compliance with medications has significant economic and therapeutic consequences (18), because non-adherence patients are at greater risk of developing complications affecting their health status and overall quality of life (19).

Patients' adherence to their anti-diabetic medications is a critical and important factor to prevent serious undesirable complications and to reduce the health care resource utilizations. Effective diabetes management mandates good provider-patient relationship, and compliance to therapies is one of the significant aspects of the relation. Poor adherence to therapies is common, especially when comorbidities exist (20), and is believed to be influenced by several factors divided into five categories: patient-centered factors, therapy-related factors, health care system factors, social and economic factors, and disease-related factors (21-23).

Studies on adherence to anti-diabetic medications among type 2 DM patients in Palestine are few (24-26), but unfortunately none of these were carried out in the Gaza Strip. It became necessary and urgently needed to highlight the current status of adherence to diabetic medications among type $2 \mathrm{DM}$ patients in the area of Gaza Strip and show the cultural differences within the same Palestinian population, with Arab-speaking countries and the overseas world. Thus, the aim of this study was to evaluate the adherence to anti-diabetic medications and examine the associated factors among type $2 \mathrm{DM}$ patients attending primary health care clinics in the Gaza Strip. In addition, this study was based on the following hypotheses:

- Adherence to anti-diabetic medication is sub-optimal among primary health care patients with type $2 \mathrm{DM}$ in the Gaza Strip.

- Elderly, duration of DM, health literacy, perception of disease's severity and treatment's benefit, and male gender are associated with adherence to medications.

\section{MATERIALS AND METHODS}

\section{Study Design and Setting}

To elaborate the study data, a cross-sectional analytical design was used in 2016. The study was conducted in the primary health centers (PHCs; level IV) distributed across four Gaza governorates. They were 9 and serve 6,486 type II diabetic patients. A cluster sample was used to select one PHC (level IV) from each governorate (North, Gaza, Middle Zone, and South) in the Gaza Strip. The four named selected PHC beginning from the north were Jabalia martyrs, Al-Rimal martyrs, Dier Al-Balah martyrs, and Khan Younis martyrs, respectively.

\section{Sample and Sampling}

Selection criteria for patients' inclusion were the following: type 2 $\mathrm{DM}$, at least 30 years old, under anti-diabetic therapies for at least 6 months at the time of enrollment, and willingness to participate in the study. Pregnant women and patients with mental diseases were excluded. The following formula was used to calculate the sample size, $n=[(\mathrm{Z} \mathrm{a} / 2) 2 \mathrm{p}(1 \mathrm{p}) / \mathrm{d} 2]$. Giving the prevalence of DM in Palestine equals or close to $10 \%(7-9)$, the sample size was 338 . Adding $10 \%$ of non-response rate, the sample size for this study was 372 patients with type 2 DM. Then, it was decided to sample proportionally to achieve representativeness of sample and gender. A list of attending patients was prepared, and randomization was applied to select the first patient; then, the next was every 17 th patient $(6,486 / 372)$. In case the patient refused to participate, we took the next one without affecting the listing order.

\section{Data Collection}

Adherence to prescribed therapies is believed to be influenced by other elements beyond the traditional socio-demographic or clinical-related factors (27). We used a structured questionnaire that has five parts: socio-demographic (age, gender, place of living, duration of DM, complications, previous hospitalization, etc.), health belief model (HBM; 16 items), patient-physician relationship (10 items), health literacy (4 items), and adherence to anti-diabetic medications (four items). The questionnaire was translated into Arabic and validated following the translation 
steps given by the Agency for Health Care Research and Quality (28). Internal consistency of the entire questionnaire examined with Cronbach's alpha value was 0.76 . Content validity was examined, by nine health experts, through the determination of item content validity index (I-CVI) and scale content validity index (S-CVI). The I-CVI and S-CVI ranged between $0.88-1.00$ and $0.97-1.00$, respectively. Inter-rater reliability measured by kappa statistic revealed a high agreement between nine raters $(k \geq 0.89)$. Three trained interviewers collected the required data by face-toface interview. Data collection took place during patient visit to the $\mathrm{PHC}$, and $15 \mathrm{~min}$ were enough to complete the questionnaire.

\section{Health Beliefs of Patients Regarding DM}

We used the HBM which was originally formulated to explain why persons would or would not undertake preventive health actions (29) and later applied to the prediction of compliance with prescribed therapies (30). The model is derived from psychological and behavioral theories and was conceptualized to enclose four elements: perceived susceptibility, perceived severity, perceived benefits, and perceived barriers. The HBM incorporated a 5-point Likert scale ( $1=$ strongly disagree to $5=$ strongly agree). The entire Cronbach's alpha was 0.70 . A score of $\geq 3$ out of 5 demonstrated that patient had health beliefs regarding DM, while negatively worded questions with the score of $<3$ demonstrated bad health belief.

\section{Patient-Provider Relationship}

Physician-patient relationship was examined by patientphysician relationship questionnaire developed by Van der FeltzCornelis and colleagues (31). The questionnaire has 10 items and is answered on 5-point Likert scale from $1=$ strongly disagree to $5=$ strongly agree. The Cronbach's alpha value of the entire 10 questions was 0.79 . A score of $\geq 3$ out of 5 demonstrates a good relationship between physician and patient.

\section{Health Literacy}

The health literacy of patients was measured using the Short Health Literacy Screening Tool (Brief Health Literacy Screening Tool; BRIEF) (32). This scale has four questions on 5-point Likert scale $(1=$ never to $5=$ always). Internal consistency was measured with Cronbach's coefficient alpha which was 0.71 . A score of $\geq 3$ out of 5 for positively worded questions demonstrates good health literacy and the score of $<3$ is bad health literacy.

\section{Adherence to Anti-Diabetic Medications}

We used the four-items Morisky Medications Adherence Scale (MMAS-4) which demonstrated a good concurrent and predictive validity and good internal consistency (33). This scale is answered with "yes" or "no." Because the four questions are negatively coded items, 0 point is given to "no" answer and 1 point is given to "yes" answer: the less score the more adherence. The score is from 0 to 4 and is classified as follows: $0=$ high adherence, $1-2=$ medium adherence, $3-4=$ low adherence. Internal consistency was examined, and Cronbach's coefficient alpha was 0.72 .

\section{Statistical Analysis}

The Statistical Package for Social Sciences (SPSS) version 22 (IBM Corp, Armonk, NY, USA) was used in data analysis, and the data were checked for outliers and errors during data entry phase. Descriptive statistics included percentages and frequencies were calculated for categorical variables, while mean and SD for continuous variables. Items' responses were collapsed into three choices "agree and strongly agree, do not know, and disagree and strongly disagree" for the patient-provider relationship and HBM questionnaires, and "always and sometimes, do not know, and rare and never" for health literacy questionnaire. Univariate analysis of data was used to determine the level of adherence, summarize the data, and describe the socio-demographic characteristics of participated patients. Crude odds ratios [ORs; 95\% confidence interval (CI)] were used to describe the strength of association between independent variables and the dependent variable (adherence to medications). Independent binary or multi-group variables, with $p$-value of 0.25 or less, were taken for binary logistic regression and multiple linear regression analysis, respectively, to determine which variables were independently associated with the dependent variable. The frequently used $p$-value of $\leq 0.05$ usually fails to recognize significant variables (34).

\section{RESULTS}

Three hundred and sixty-nine patients participated in the study, and their mean age $( \pm S D)$ was $56.38 \pm 10.36$. More than half (55.8\%) were females and $352(95.4 \%)$ were married. With regard to clinical characteristics, 180 (48.8\%) have no comorbidities; 42 (11.4\%) have hypertension; 26 (7\%) have retinopathy, and 104 $(28.2 \%)$ presented with nephropathy. A majority of patients $(321 ; 87 \%)$ were not previously hospitalized and were under oral hypoglycemic agent $(241 ; 65.3 \%)$, while $85(23 \%)$ were under insulin treatment. Mean duration $( \pm S D)$ of having DM was 10.48 (8.12) and two-third of them have DM for more than 5 years (234; $63.4 \%)$. Good glycemic control $(\leq 6.4 \%)$ was found in $41(11.1 \%)$ patients.

\section{Response by Items}

Answers for patient-physician relationship, health literacy, and HBM were collapsed into three main choices, and the mean (SD) is presented accordingly (Table 1). Mean score (SD) of $\mathrm{HBM}$ and patient-provider relationship questionnaire were above the recommended cutoff which demonstrates good health belief about DM and relationship between patients and their providers [3.6 (0.38) and $4.4(0.55)$, respectively]. However, mean score (SD) of health literacy questionnaire was below the recommended cutoff which means bad health literacy [2.9 (0.59)].

\section{Adherence to Medications}

Two hundred and fourteen patients (58\%) were considered highly adherent (MMAS = 0), 146 (39.5\%) were medially adherent (MMAS $=1-2$ ), and nine $(2.5 \%)$ had low adherence (MMAS $\geq 3)$. Almost one-third $(125 ; 33.9 \%)$ forgot to take their prescribed medications; $39(10.6 \%)$ were careless at times to take the medicine; $28(7.6 \%)$ revealed that they stopped taking the anti-diabetic medications when they felt bad for taking the 
TABLE 1 | Mean (SD), percentage of agree, do not know, and disagree of questionnaire items.

\begin{tabular}{|c|c|c|c|c|}
\hline Questions & M (SD) & Agree, $n(\%)$ & Do not know, $n(\%)$ & Disagree, $n(\%)$ \\
\hline A: Health belief model & $3.6(0.38)$ & & & \\
\hline My diabetes is well controlled & $3.0(1.24)$ & $161(43.6)$ & $9(2.4)$ & $199(53.9)$ \\
\hline My diabetes would be worse if I did nothing about it & $4.5(0.6)$ & $361(97.8)$ & $2(0.5)$ & $6(1.6)$ \\
\hline I believe my medication will help prevent complications related to diabetes & $4.5(0.62)$ & $358(97)$ & $5(1.4)$ & $6(1.6)$ \\
\hline Diabetes can be a serious disease if I do not control it & $4.6(0.69)$ & $354(95.9)$ & $1(0.3)$ & $14(3.8)$ \\
\hline My diabetes is not a problem for me as long as I feel all right & $3.6(1.35)$ & $236(64)$ & $4(1.1)$ & $129(35)$ \\
\hline aMy diabetes will have bad effect on my future health & $1.6(0.65)$ & $350(94.9)$ & $12(3.3)$ & $7(1.9)$ \\
\hline aMy diabetes will cause me to be sick a lot & $1.6(0.66)$ & $353(95.7)$ & $6(1.6)$ & $10(2.7)$ \\
\hline I believe I will always need my diabetic medications & $4.4(0.77)$ & 349 (94.6) & $2(0.5)$ & $18(4.9)$ \\
\hline I believe I can control my diabetes & $3.6(1.22)$ & $248(67.2)$ & $3(0.8)$ & $118(32)$ \\
\hline I believe that my medications will control my diabetes & $4.3(0.74)$ & $348(94.3)$ & $2(0.5)$ & $19(5.1)$ \\
\hline If I change my eating habits, it will probably help me & $4.2(0.94)$ & $323(87.5)$ & $5(1.4)$ & $41(11.1)$ \\
\hline My medicine makes me feel better & $4.3(0.63)$ & $357(96.7)$ & $2(0.5)$ & $10(2.7)$ \\
\hline I would have to change too many habits to follow my medications & $4.1(1.06)$ & 307 (83.2) & $1(0.3)$ & $61(16.5)$ \\
\hline alt has been difficult following the medications prescribed for me & $4.5(0.81)$ & $21(5.7)$ & $3(0.8)$ & $345(93.5)$ \\
\hline a cannot understand what the doctor told me about my diet (medications) & $4.6(0.72)$ & $13(3.5)$ & $2(0.5)$ & $354(95.9)$ \\
\hline aTaking my medications interferes with my normal daily activities & $4.3(0.99)$ & $40(10.8)$ & $2(0.5)$ & $327(88.6)$ \\
\hline B: Physician-patient relationship & $4.4(0.55)$ & & & \\
\hline I trust my doctor & $4.4(0.67)$ & $357(96.7)$ & $1(0.3)$ & $11(3)$ \\
\hline My doctor is dedicated to help me & $4.5(0.57)$ & $363(98.4)$ & $2(0.5)$ & $4(1.1)$ \\
\hline I can talk to my doctor & $4.4(0.66)$ & $360(97.6)$ & - & $9(2.4)$ \\
\hline My doctor has enough time for me & $4.3(0.78)$ & $349(94.6)$ & - & $20(5.4)$ \\
\hline I feel content with my doctor's treatment & $4.4(0.71)$ & $357(96.7)$ & - & $12(3.3)$ \\
\hline I find my doctor easily accessible & $4.5(0.55)$ & $366(99.2)$ & - & $3(0.8)$ \\
\hline My doctor is dedicated to help me & $4.5(0.55)$ & 367 (99.5) & - & $2(0.5)$ \\
\hline My doctor understands me & $4.4(0.56)$ & $366(99.2)$ & - & $3(0.8)$ \\
\hline My doctor and I agree on the nature of my medical symptoms & $4.4(0.71)$ & $357(96.7)$ & $1(0.3)$ & $11(3)$ \\
\hline \multirow[t]{2}{*}{ I benefit from the treatment of my doctor } & $4.5(0.55)$ & $365(98.9)$ & $1(0.3)$ & $3(0.8)$ \\
\hline & $M(S D)$ & Always $n(\%)$ & Do not know, $n(\%)$ & Never $n(\%)$ \\
\hline C: Health literacy & $2.9(0.59)$ & & & \\
\hline $\begin{array}{l}\text { aHow often do you have problems learning about your medical condition because of difficulty } \\
\text { understanding written information? }\end{array}$ & $4.3(1.45)$ & $68(18.4)$ & $5(1.4)$ & $296(80.2)$ \\
\hline How often do you have someone help you read primary health center materials? & $3.9(1.49)$ & $274(74.3)$ & $2(0.5)$ & $93(25.2)$ \\
\hline aHow confident are you filling out medical forms by yourself? & $4.5(1.16)$ & $47(12.7)$ & $5(1.4)$ & $317(85.9)$ \\
\hline In general, how easy or hard do you find it to understand medical statistics? & $4.6(0.91)$ & $344(93.2)$ & - & $25(6.8)$ \\
\hline
\end{tabular}

${ }^{a}$ Negatively worded question.

TABLE 2 | Patients' self-reported adherence to medications by the Morisky Medication Adherence Scale.

Item

Number of patients answered no (\%)

aDo you ever forget to take your medicine? aAre you careless at times to take your medicine?

aSometimes if you feel worse when you take the

$244(66.1)$ $330(89.4)$ $341(92.4)$

medicine, do you stop taking it?

aWhen you feel better, do you sometimes stop taking your $\quad 351$ (95.1) medicine?

Adherence to medication (overall)

Distribution of scores

0

$214(58.0)$

109 (29.5)

37 (10.0)

9 (2.5)

${ }^{a}$ Negatively worded question.

medications; and 18 (4.9\%) reported that they sometimes stopped taking medicines when they felt better. Table 2 presents numbers and percentage of patients who answered "no" by the MMAS- 4 .

\section{Factors Influenced High Adherence to Anti-Diabetic Therapies}

The number of patients who showed low adherence was very low, and therefore we divided patients into two groups: high adherent group (MMAS score $=0$ ) and intermediate adherent (MMAS score $=1,2,3$, and 4 ). At crude analysis using the univariate analysis of independent variables, nine independent variables, including but not limited to age $(\mathrm{OR}=1.72,95 \% \mathrm{CI}: 0.858-3.343)$, gender $(\mathrm{OR}=0.681,95 \% \mathrm{CI}: 0.447-1.036)$, duration of DM $(\mathrm{OR}=1.046$, 95\% CI: $0.607-1.803)$, and health literacy $(\mathrm{OR}=1.823,95 \% \mathrm{CI}$ : 0.664-5.006) were selected for logistic and multiple linear regression model $(p \leq 0.25)$. Details are presented in Table 3 .

\section{Independent Factors Associated with Adherence to Medications}

Findings of logistic regression for binary variables demonstrated factors associated with adherence to anti-diabetic medications were female gender $(\mathrm{OR}=1.657,95 \% \mathrm{CI}: 1.065-2.578)$ and perceived the severity of DM (OR $=1.510,95 \% \mathrm{CI}$ : $0.410-5.560$; Table 4). The more the patients with diabetes perceive the severity of DM, the more likely to highly adhere to their regimens. Using 
TABLE 3 | Factors associated with high adherence to anti-diabetic therapies.

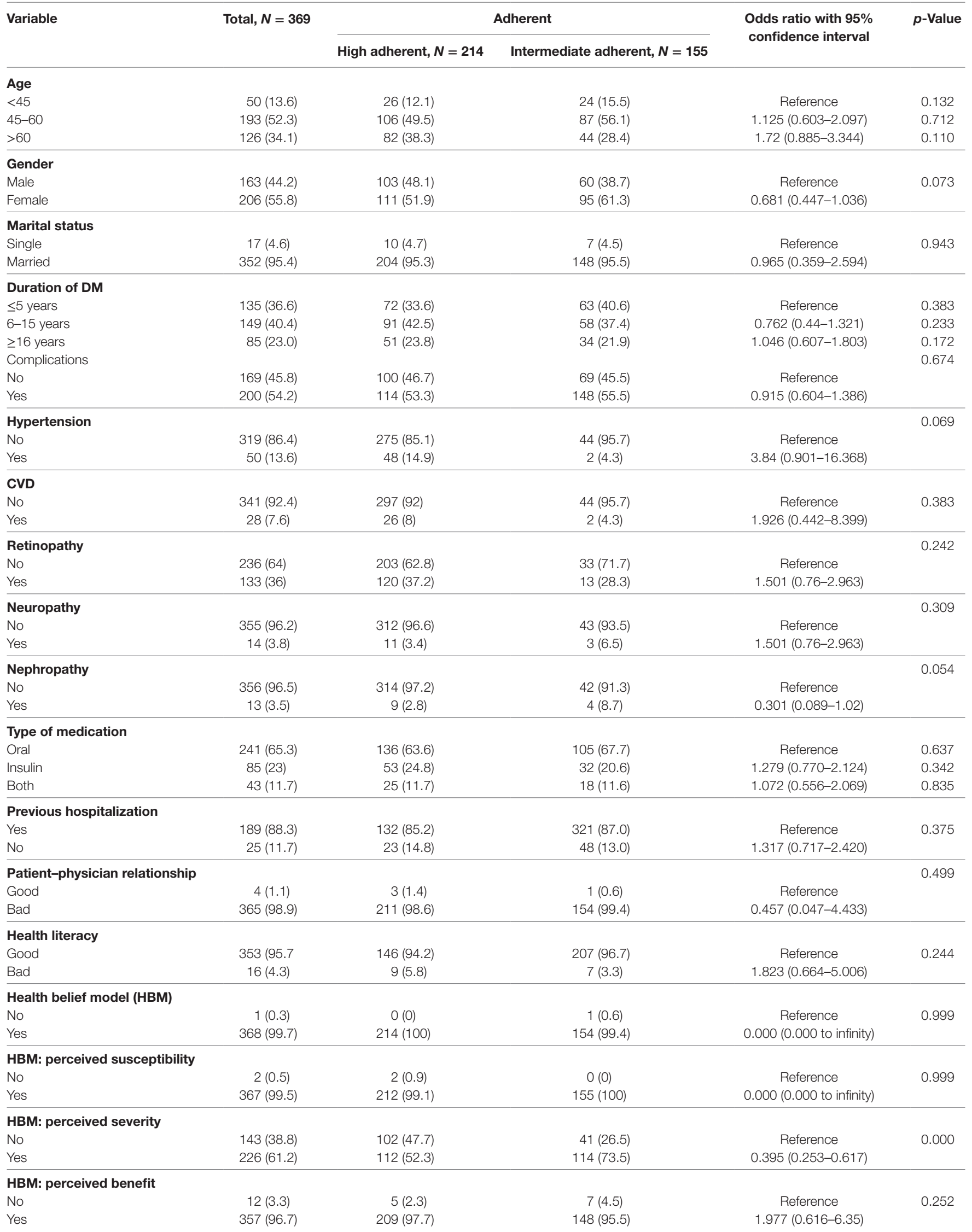


TABLE 4 | Logistic regression model for independent variables to predict adherence.

\begin{tabular}{|c|c|c|c|c|c|}
\hline Variable & $B$ & SE & Wald & $p$-Value & Odds ratio with $95 \%$ confidence interval \\
\hline Constant & -0.478 & 0.825 & 0.336 & 0.562 & \\
\hline Gender & 0.505 & 0.226 & 5.008 & 0.025 & $1.657(1.065-2.578)$ \\
\hline Hypertension & 0.524 & 0.342 & 2.355 & 0.125 & $1.689(0.865-3.300)$ \\
\hline Retinopathy & 0.156 & 0.232 & 0.455 & 0.500 & $1.169(0.742-1.841)$ \\
\hline Nephropathy & -0.656 & 0.600 & 1.194 & 0.274 & $0.519(0.16-1.683)$ \\
\hline Health Literacy & 0.690 & 0.546 & 1.599 & 0.206 & $1.994(0.684-5.812)$ \\
\hline Health belief model (HBM; severity) & -0.990 & 0.235 & 17.764 & 0.000 & $0.372(0.234-0.589)$ \\
\hline HBM (benefit) & 0.466 & 0.625 & 0.555 & 0.456 & $1.593(0.468-5.426)$ \\
\hline
\end{tabular}

the multiple linear regression, two factors predict adherence to anti-diabetic therapies, after adjustment or controlling other factors, were: older age $(t$-test $=1.345)$ and longer duration of DM $(t$-test $=0.899)$, but were not statistically significant (Table 5).

\section{DISCUSSION}

In our study, we reported 214 (58\%), 146 (39.5\%), and nine $(2.5 \%)$ of primary care patients with type $2 \mathrm{DM}$, under treatment with either oral medications alone or with insulin, had high, medium, and low adherence, respectively. The information on adherence was based on patients' recall, and therefore the actual and true prevalence of compliance could be lesser than the presented findings in this study. In addition, patients might have difficulties in remembering their habits and medications taking practices, but this was diminished by asking patients to memorize within a period of 2 weeks only. The reported adherence to this study was suboptimal and lower than previous findings reported from Iran (74.8\%) (35), and Nigeria (72.5\%) (36). However, Ahmad et al. (37) reported a lower rate of adherence than our finding (47\%). The differences in adherence level could be attributed to factors related to the health care settings, and/ or socio-economic status, and/or metrics used for adherence assessment. Another possible explanation could be the context of Gaza Strip, in which the treatments are only available for few days from the beginning of each month, and therefore if patients did not get their treatments on time, they have to buy them from own pockets, which overburden the financial and economical responsibility of patients to afford the necessary medications. However, treatments could be available for free in other contexts.

We also found that the level of adherence to medications was associated with patients' belief about the severity of disease, which reflects the feelings concerning the seriousness of contracting an illness or leaving it untreated. This is enough explained on health psychology model presented in HBM and the Theory of Planned Behaviors $(30,38)$. The majority of our primary care patients sensitized the severity of DM on their health in future, and therefore $94.6 \%$ stated that they are in need for diabetes treatments. Negative beliefs about medications and disease are a potent barrier factors to proper adherence $(39,40)$. It is necessary to address patients' belief about the severity of disease, the benefit of treatments, and possible challenging factors, through health education, that contribute to preventing patients from adherence to their therapies. Many studies, from Europe, Africa, and the
TABLE 5 | Multivariate analysis of factors associated with adherence.

\begin{tabular}{|c|c|c|c|c|c|c|}
\hline \multirow[t]{2}{*}{ Predictors } & \multirow[t]{2}{*}{$B$} & \multirow[t]{2}{*}{ SE } & \multirow[t]{2}{*}{$t$} & \multirow[t]{2}{*}{$p$-Value } & \multicolumn{2}{|c|}{$\begin{array}{l}95 \% \text { confidence } \\
\text { interval for } B\end{array}$} \\
\hline & & & & & Lower & Upper \\
\hline Constant & 0.354 & 0.138 & 2.562 & 0.011 & 0.082 & 0.626 \\
\hline Age & 0.003 & 0.003 & 1.345 & 0.180 & -0.002 & 0.008 \\
\hline Duration & 0.003 & 0.003 & 0.899 & 0.369 & -0.004 & 0.010 \\
\hline
\end{tabular}

USA, ensured the importance of having diabetes health education to improve patients' adherence to their medications (41-43). There is a need to raise patients' awareness and sensitization about disease and management plan. Possible ways to achieve it could be through the self-management education of diabetes, meeting with a diabetes educator on a regular basis, use of educational materials, establish a community campaign, improve communication between patients and health care providers, and patients' self-management of diabetes (44).

Females were more likely than males to be adherent to their therapies which is consistent with a research conducted among patients suffering from tuberculosis in Thailand (45). The gender's effect on adherence rate is contradictory, in which previous studies have shown non-adherence was associated with female $(46,47)$. A possible explanation for our findings, but remains a source of speculations, is that women are more proactive than men toward following preventive care and seeking medical care to obtain treatments for medical conditions. Moreover, adherence to anti-diabetic medications is challenged with complex regimens especially when comorbidities exist, and so men forget to take their therapies as they are exhausted with work. In addition, a possible higher rate of medications' side effect could be a reason behind low adherence among men. Also, some studies did not find possible relations between gender and adherence to medications $(48,49)$.

Old age ( $\geq 60$ years) was a predictor of good adherence, but the finding was not statistically significant. A recent systematic review conducted by Krueger et al. (50) reported similar findings regarding the relationship between older age ( $>60$ years) and adherence to medications among patients with congestive heart failure. Other studies of patients with heart problems were also in line with our finding $(51,52)$. Common cause for non-adherence among younger ones could be attributed to new diagnosis (53), limited knowledge of the disease (54), fear of side effect, and burden of regimens $(55,56)$. Older patients with longer duration 
of having the disease receive proper support for diabetes management and are more aware of the importance of glycemic control to prevent potential complications and so survive with better quality of life (55). Furthermore, social support given by families in Gaza to be in charge of elderly could be one of the contributing factors to adherence to medications.

Duration of DM was predicted to be an important factor related to adherence to medications but was not statistically significant. The longer the patients have diabetes history, the more likely they will be adherent to the prescribed regimens. This finding is consistent with previous publications (57). A possible explanation is that patients during the early years of disease are not aware of the risk of disease and its serious complications. But when complications start and suffering from disease begins, the attitude toward the disease and related therapies may change leading to a better adherence to medications and providers' instructions. Furthermore, patients with longer duration of disease are more likely to interact better with their health care providers, understand their treatment plans, and become more aware of their diseases. However, Giemens et al. (58) and Arifulla et al. (59) found a negative relationship between the duration of diabetes and patients' adherence to medications. Sweileh et al. (60) found no significant relation between the duration of DM disease and adherence to treatments. In view of controversies, we recommend further prospective studies to improve future management and to find out the possible contribution of adherence to medications to patients' survival.

This study has many limitations: first, the use of self-report method and the simplest and inexpensive method, to evaluate patients' adherence to anti-diabetic medications. Second, selfreport methods usually over-estimate patients' adherence level. However, Goerge et al. (61) stated that using a valid scale such as the MMAS, the measured adherence level is accurate since the sensitivity and specificity are more than $70 \%$. Third, there was a lack of information about the history of joining educational sessions about diabetes, and the level of education. Fourth, selection bias could happen among primary care patients since those who seek health care are only who care about their health and best. Fifth, reasons for non-adherence were not addressed in this study. The strengths of this study are: first, the randomization applied when selecting PHC and patients; second, gender representativeness in the study sample; and third, the sample size was relatively large and enough to evaluate adherence and factors associated.

\section{Policy Implications}

In the light of study findings, $\mathrm{MoH}$ as the stewardship body and responsible for the health of people has to initiate policies and take actions that contribute to the promotion of adherence to medications among type $2 \mathrm{DM}$. Among these policies are: improving the provider-patient relationship and building a trust relation; making the treatments accessible at the time of use; enhancing the self-management and self-monitoring of blood glucose; and providing patients with a degree of autonomy motivation to ensure optimum glycemic control. Moreover, MoH should establish a diabetes education service to raise patients' awareness of DM and enhance health belief perception toward the benefit of treatments, severity, and susceptibility of non-adherence in the occurrence of complications.

\section{CONCLUSION}

This study showed that patients' adherence to anti-diabetic medication was suboptimal and variations were found between high adherent and intermediate adherent with regard to, but not limited to, age, gender, duration of DM, health literacy, health belief, and the absence of co-morbidities. The longer duration of having the disease, old age, female gender, and patient's self-perception and belief about the severity of DM are factors associated with adherence to medications. Enhancing patients' knowledge and recognition with diabetes, through diabetes educator, is necessary to improve self-management of DM and increase the rate of adherence. Increasing interactions and have a partner relationship with patients are keys to improve patients' adherence to medications.

\section{ETHICS STATEMENT}

This study received the ethical approval from Palestinian Ethical Research Committee (No: PHRC/HC/118/16 on 06/Jun/2016). This is an independent regional body that comprises members of government and external professionals and researchers. A permission was also obtained from Ministry of Health to visit the selected primary health care centers and conduct the study. Patients were informed about their right to withdraw from the study at anytime without any harmful consequences. Moreover, we verbally stressed on the voluntary participation in the study, giving the right to withdraw at any time without any consequences. The study was conducted over a period of 3 months starting from October 2016.

\section{AUTHOR CONTRIBUTIONS}

AE, MR, and HS developed the conception and design of this study; AA analyzed and interpreted the analyzed data; AE drafted the manuscript; $\mathrm{AE}, \mathrm{MR}, \mathrm{AA}$, and $\mathrm{HS}$ revised the manuscript, provided final approval of the manuscript, and approved this manuscript.

\section{ACKNOWLEDGMENTS}

The authors express their sincere thanks to PMRS for funding this research and to $\mathrm{MoH}$ for its support in making this study real. In addition, they are grateful to all patients who participated in this study.

\section{FUNDING}

This study was funded by the Palestinian Medical Relief Society (PMRS) - special grant for research in priority areas of noncommunicable diseases (2016/2017) (BMZ-2014-1819.3). 


\section{REFERENCES}

1. International Diabetes Federation (IDF). Diabetes and Impaired Glucose Tolerance. 6th ed. Brussels: Diabetes Atlas (2013). p. 58-9.

2. Anjana RN, Ali NK, Pradeepa R, Deepa M, Datta M, Unnikrishnan R, et al. The need for obtaining accurate nationwide estimates of diabetes prevalence in India - rationale for a national study on diabetes. Indian J Med Res (2011) 133:369-80.

3. Aschner P, Beck-Nielsen H, Bennett P, Boulton A, Colagiuri R. Diabetes and Impaired Glucose Tolerance. 5th ed. Brussels: IDF Diabetes Atlas (2012).

4. Harries AD, Satyanarayana S, Kumar AMV, Nagaraja SB, Isaakidis P, Malhotra S, et al. Epidemiology and interaction of diabetes mellitus and tuberculosis and challenges for care: a review. Public Health Action (2013) 3:S3-9. doi:10.5588/pha.13.0024

5. Shaw JE, Sicree RA, Zimmet PZ. Global estimates of the prevalence of diabetes for 2010 and 2030. Diabetes Res Clin Pract (2009) 87:4-14. doi:10.1016/j. diabres.2009.10.007

6. Whiting DR, Guariguata L, Weil C, Shaw J. IDF diabetes atlas: global estimates of the prevalence of diabetes for 2011 and 2030. Diabetes Res Clin Pract (2011) 94:311-21. doi:10.1016/j.diabres.2011.10.029

7. Abdul-Rahim HF, Husseini A, Giacaman R, Jervell J, Bjertness E. Diabetes mellitus in an urban Palestinian population: prevalence and associated factors. East Mediterr Health J (2001) 7:67-78.

8. Husseini A, Abdul-Rahim H, Awartani F, Jervell J, Bjertness E. Prevalence of diabetes mellitus and impaired glucose tolerance in a rural Palestinian population. East Mediterr Health J (2000) 6:1039-45.

9. Husseini A, Abdul-Rahim H, Awartani F, Giacaman R, Jervell J, Bjertness E. Type 2 diabetes mellitus, impaired glucose tolerance and associated factors in a rural Palestinian village. Diabet Med (2000) 17:746-8. doi:10.1046/j. 1464-5491.2000.00355.x

10. Abu-Rmeileh NM, Husseini A, O'FlahertyM, Shoaibi A, CapewellS. Forecasting prevalence of type 2 diabetes mellitus in Palestinians to 2030: validation of a predictive model. Lancet (2012) 380:S21. doi:10.1016/S0140-6736(13)60202-0

11. MinistryofHealth;PHIC.HealthStatusinPalestine, 2014.(2015).Availablefrom: http://www.moh.ps/Content/Books/kD3bquHr7jbwK9f6VQJAsLDCuckg EDlCZUFa9ssb62m9Eim2le562D_ECDSNEboZRJwc6HyiggSMzKUPMe DJa2vkBNlAdZOGlvNuS9CHKJjGO.pdf

12. World Diabetes Foundation. In West Bank and Gaza Strip, Comprehensive Care Gets Results. (2015). Available from: http://www.worlddiabetesfoundation.org/news/westbank-and-gaza-strip-comprehensive-care getsresults

13. Obaid H, Eljedi A. Risk factors for the development of diabetic foot ulcers in Gaza strip: a case-control study. Int J Diabetes Res (2015) 4(1):1-6. doi:10.5923/j.diabetes.20150401.01

14. Salah M. Who are diabetic foot patients? A hospital based descriptive study in the Gaza governorate. JUS China Med Sci (2016) 13:220-6. doi:10.17265/1548-6648/2016.04.006

15. Sharif NE, Samara I, Titi I, Awartani A. Compliance with and knowledge about diabetes guidelines among physicians and nurses in Palestine. East Mediterr Health J (2016) 21(11):791-802.

16. Farsaei S, Sabzghabaee AM, Zargarzadeh AH, Amini M. Adherence to glyburide and metformin and associated factors in type 2 diabetes in Isfahan, Iran. Iran J Pharm Res (2011) 10:933-9.

17. Osterberg L, Blaschke T. Adherence to medication. N Engl J Med (2005) 353:487-97. doi:10.1056/NEJMra050100

18. Ho PM, Rumsfeld JS, Masoudi FA, McClure DL, Plomondon ME, Steiner JF, et al. Effect of medication nonadherence on hospitalization and mortality among patients with diabetes mellitus. Arch Intern Med (2006) 166:1836-41. doi:10.1001/archinte.166.17.1836

19. da Mata AR, Álvares J, Diniz LM, da Silva MR, Alvernaz dos Santos BR, Guerra Júnior AA. Quality of life of patients with diabetes mellitus types 1 and 2 from a referral health centre in Minas Gerais, Brazil. Expert Rev Clin Pharmacol (2016) 9(5):739-46. doi:10.1586/17512433.2016.1152180

20. Kardas P. The DIACOM study (effect of dosing frequency of oral antidiabetic agents on the compliance and biochemical control of type 2 diabetes). Diabetes Obes Metab (2005) 7:722-8. doi:10.1111/j.1463-1326.2004.00462.x

21. Wong MCS, Kong APS, So W-Y, Jiang JY, Chan JCN, Griffiths SM. Adherence to oral hypoglycemic agents in 26,782 Chinese patients: a cohort study. J Clin Pharmacol (2011) 51:1474-82. doi:10.1177/0091270010382911
22. Hutchins V, Zhang B, Fleurence RL, Krishnarajah G, Graham J. A systematic review of adherence, treatment satisfaction and costs, in fixed-dose combination regimens in type 2 diabetes. Curr Med Res Opin (2011) 27:1157-68. doi: 10.1185/03007995.2011.570745

23. Rwegerera GM. Adherence to anti-diabetic drugs among patients with type 2 diabetes mellitus at Muhimbili National Hospital, Dar es Salaam, Tanzania - a cross-sectional study. Pan Afr Med J (2014) 17:252. doi:10.11604/pamj.2014. 17.252.2972

24. Jamous RM, Sweileh WM, Abu-Taha AS, Sawalha AF, Zyoud SH, Morisky DE. Adherence and satisfaction with oral hypoglycemic medications: a pilot study in Palestine. Int J Clin Pharm (2011) 33:942-8. doi:10.1007/s11096-011-9561-7

25. Sweileh WM, Ihbesheh MS, Jarar IS, Taha AS, Sawalha AF, Zyoud SH, et al. Self-reported medication adherence and treatment satisfaction in patients with epilepsy. Epilepsy Behav (2011) 21:301-5. doi:10.1016/j.yebeh.2011. 04.011

26. Sweileh WM, Zyoud SH, Abu Nab’a RJ, Deleq MI, Enaia MI, Nassar SM, et al. Influence of patients' disease knowledge and beliefs about medicines on medication adherence: findings from a cross-sectional survey among patients with type 2 diabetes mellitus in Palestine. BMC Public Health (2014) 14:94. doi:10.1186/1471-2458-14-94

27. Vermeire E, Hearnshaw H, Van Royen P, Denekens J. Patient adherence to treatment: three decades of research. A comprehensive review. J Clin Pharm Ther (2001) 26:331-42. doi:10.1046/j.1365-2710.2001.00363.x

28. Agency for Healthcare Research and Quality. Translation Guidelines for the AHRQ Surveys on Patient Safety Culture. (2010). Available from: https://www. ahrq.gov/sites/default/files/wysiwyg/professionals/quality-patientsafety/ patientsafetyculture/resources/transguide.pdf

29. Rosenstock IM. The health belief model and preventive health behavior. In: Becker MH, editor. The Health Belief Model and Personal Health Behavior. Thorofare, NJ: Charles B. Slack, Inc. (1974). p. 27-59.

30. Becker MH. The health belief model and sick role behavior. In: Becker $\mathrm{MH}$, editor. The Health Belief Model and Personal Health Behavior. Thorofare, NJ: Charles B. Slack, Inc. (1974). p. 82-92.

31. Van der Feltz-Cornelis CM, Van Oppen P, Van Marwijk HW, De Beurs E, Van Dyck R. A patient doctor relationship questionnaire (PDRQ 9) in primary care: development and psychometric evaluation. Gen Hosp Psychiatry (2004) 26:115-20. doi:10.1016/j.genhosppsych.2003.08.010

32. Haun J, Noland-Dodd V, Varnes J, Graham-Pole J, Rinzo B, Donaldson P. Testing the BRIEF health literacy screening tool. Fed Pract (2009) 26:24-31.

33. Morisky DE, Green LW, Levine DM. Concurrent and predictive validity of a self-reported measure of medication adherence. Med Care (1986) 24:67-74. doi:10.1097/00005650-198601000-00007

34. Mickey R, Greenland S. The impact of confounder selection criteria on effect estimation. Am J Epidemiol (1989) 129:125. doi:10.1093/oxfordjournals.aje. a115101

35. Yekta Z, Pourali R, Aghassi MR, Ashragh N, Ravanyar L, Pour MYR. Assessment of self-care practice and its associated factors among diabetic patients in urban area of Urmia, northwest of Iran. J Res Health Sci (2011) 11:33-7.

36. Pascal IGU, Ofoedu JN, Uchenna NP, Nkwa AA, Uchamma GUE. Blood glucose control and medication adherence among adult type 2 diabetic Nigerians attending a primary care clinic in under-resourced environment of eastern Nigeria. N Am J Med Sci (2012) 4:310-5. doi:10.4103/1947-2714.98590

37. Ahmad NS, Ramli A, Islahudin F, Paraidathathu T. Medication adherence in patients with type 2 diabetes mellitus treated at primary health clinics in Malaysia. Patient Prefer Adherence (2013) 17(7):525-30. doi:10.2147/PPA.S44698

38. Ajzen I. From intentions to actions: a theory of planned behavior. In: Kuhl J, Beckmann J, editors. Action Control: From Cognition to Behavior. Heidelberg: Springer Verlag (1985). p. 11-39.

39. Chummun H, Boland D. How patient beliefs affect adherence to prescribed medication regimens. Br JNurs (2013) 22:270-6. doi:10.12968/ bjon.2013.22.5.270

40. Sirey JA, Greenfield A, Weinberger MI, Bruce ML. Medication beliefs and self-reported adherence among community-dwelling older adults. Clin Ther (2013) 35:153-60. doi:10.1016/j.clinthera.2013.01.001

41. Bagonza1 J, Rutebemberwa E, Bazeyo W. Adherence to anti diabetic medication among patients with diabetes in eastern Uganda; a cross sectional study. BMC Health Serv Res (2015) 15:168. doi:10.1186/s12913-015-0820-5 
42. Lorenzi GM, LaRue SM, Collins SE. Effects of a patient education support program on pramlintide adherence. Clin Diabetes (2011) 29:17-24. doi:10.2337/ diaclin.29.1.17

43. Rothschild SK, Martin MA, Swider SM, Tumialán Lynas CM, Janssen I, Avery EF, et al. Mexican American trial of community health workers: a randomized controlled trial of a community health worker intervention for Mexican Americans with type 2 diabetes mellitus. Am J Public Health (2014) 104:1540-8. doi:10.2105/AJPH.2013.301439

44. Mensing C, Boucher J, Cypress M, Weinger K, Mulcahy K, Barta P, et al. National standards for diabetes self-management education. Diabetes Care (2002) 25:s140-7. doi:10.2337/diacare.25.2007.S140

45. Lertmaharit S, Kamol-Ratankul P, Sawert H, Jittimanee S, Wangmanee S. Factors associated with compliance among tuberculosis patients in Thailand. J Med Assoc Thai (2005) 88:149-56.

46. Kalyango JN, Owino E, Nambuya AP. Non-adherence to diabetes treatment at Mulago Hospital in Uganda: prevalence and associated factors. Afr Health Sci (2008) 8(2):67-73.

47. Sajith M, Pankaj M, Pawar A, Modi A, Sumariya R. Medication adherence to antidiabetic therapy in patients with type 2 diabetes mellitus. Int J Pharm Pharm Sci (2014) 6(2):564-70.

48. Al-Qazaz HK, Sulaiman SA, Hassali MA, Shafie AA, Sundram S, Al-Nuri R, et al. Diabetes knowledge, medication adherence and glycemic control among patients with type 2 diabetes. Int J Clin Pharm (2011) 33:1028-35. doi:10.1007/ s11096-011-9582-2

49. Sweileh WM, Zyoud SH, Abu Nab'a RJ, Deleq MI, Enaia MI, Nassar SM, et al. Influence of patients' disease knowledge and beliefs about medicines on medication adherence: findings from a cross-sectional survey among patients with type 2 diabetes mellitus in Palestine. BMC Public Health (2014) 14:94. doi:10.1186/1471-2458-14-94

50. Krueger K, Botermann L, Schorr SG, Griese-Mammen N, Laufs U, Schulz M. Age-related medication adherence in patients with chronic heart failure: a systematic literature review. Int J Cardiol (2015) 184:728-35. doi:10.1016/j.ijcard.2015. 03.042

51. Wong CM, Hawkins NM, Jhund PS, MacDonald MR, Solomon SD, Granger CB, et al. Clinical characteristics and outcomes of young and very young adults with heart failure: the CHARM programme (Candesartan in Heart Failure Assessment of Reduction in Mortality and Morbidity). J Am Coll Cardiol (2013) 62:1845-54. doi:10.1016/j.jacc.2013.05.072
52. Wu J, Moser DK, Lennie TA, Burkhart PV. Medication adherence in patients who have heart failure: a review of the literature. Nurs Clin North Am (2008) 43:133-53. doi:10.1016/j.cnur.2007.10.006

53. Rodgers PT, Ruffin DM. Medication nonadherence: part II-a pilot study in patients with congestive heart failure. Manag Care Interface (1998) 11:67-9,75.

54. Huang LH. Medication-taking behaviour of the elderly. Kaohsiung J Med Sci (1996) 12:423-33.

55. vanderWalML, Jaarsma T, MoserD, VeegerN, van Gilst WH, van Veldhuisen DJ. Compliance in heart failure patients: the importance of knowledge and beliefs. Eur Heart J (2006) 27:434-40. doi:10.1093/eurheartj/ehi603

56. van der Wal ML, Jaarsma T. Adherence in heart failure in the elderly: problem and possible solutions. Int J Cardiol (2008) 125:203-8. doi:10.1016/j. ijcard.2007.10.011

57. Arslan E. Tip 2 Diabetes Mellituslu Hastaları Tedaviye Uyumların Etkileyen Faktörler. Diyarbakır: Dicle Üniversitesi (2011). p. 37-8.

58. Gimenes HT, Zanetti ML, Haas VJ. Factors related to patient adherence to antidiabetic drug therapy. Rev Lat Am Enfermagem (2009) 17:46-51. doi:10.1590/S0104-11692009000100008

59. Arifulla M, John LJ, Sreedharan J, Muttappallymyalil J, Basha SA. Patients' adherence to anti-diabetic medications in a hospital at Ajman, UAE. Malays J Med Sci (2014) 21:44-9.

60. Sweileh MW, Aker O, Hamooz S. Rate of compliance among patients with diabetes mellitus and hypertension. An-Najah Univ J Res (Nat Sci) (2005) 19:1-12.

61. George CF, Peveler RC, Heiliger S, Thompson C. Compliance with tricyclic antidepressants: the value of four different methods of assessment. Br J Clin Pharmacol (2000) 50:166-71. doi:10.1046/j.1365-2125.2000.00244.x

Conflict of Interest Statement: The authors declare that there is no conflict of interests regarding the publication of this paper.

Copyright (C) 2017 Elsous, Radwan, Al-Sharif and Abu Mustafa. This is an openaccess article distributed under the terms of the Creative Commons Attribution License (CC BY). The use, distribution or reproduction in other forums is permitted, provided the original author(s) or licensor are credited and that the original publication in this journal is cited, in accordance with accepted academic practice. No use, distribution or reproduction is permitted which does not comply with these terms. 